\title{
Dental fear and anxiety in older children: an association with parental dental anxiety and effective pain coping strategies
}

This article was published in the following Dove Press journal:

Journal of Pain Research

20 August 2014

Number of times this article has been viewed

\section{Anka Coric' \\ Adriana Banozic ${ }^{2}$ \\ Miro Klaric ${ }^{3}$ \\ Katarina Vukojevic ${ }^{4}$ \\ Livia Puljak ${ }^{5}$}

'School of Medicine, University of Mostar, Health Center Mostar, Mostar, Bosnia and Herzegovina; ${ }^{2}$ Laboratory for Pain Research, University of Split School of Medicine, Split, Croatia; ${ }^{3}$ Department of Psychiatry, School of Medicine, University of Mostar, Mostar, Bosnia and Herzegovina; ${ }^{4}$ Department of Anatomy, University of Split School of Medicine, Split, Croatia; ${ }^{5}$ Laboratory for Pain Research, University of Split School of Medicine, Split, Croatia
Correspondence: Livia Puljak University of Split School of Medicine, Soltanska 2, 21000 Split, Croatia

Tel +385 2I 557807

Fax +385 21 557811

Email livia@mefst.hr
Abstract: An association between dental fear and anxiety (DFA) has been confirmed for children younger than 8 years, but this association in older children is less clear. The aim of this study was to fill this knowledge gap by studying DFA in older children and their parents with validated measures. This cross-sectional study, conducted at Community Health Centre Mostar, Bosnia and Herzegovina, included 114 children and their parents. DFA, coping, and sociodemographic variables were studied using Corah Dental Anxiety Questionnaire (CDAS), Dental Subscale of the Children's Fear Survey Schedule (CFSS-DS), Dental Cope Questionnaire, and sociodemographic questionnaire. Maternal CDAS scores had significant positive correlation with child DFA measured with CFSS-DS $(r=0.35, P<0.001)$ and CDAS $(r=0.32$, $P<0.001)$. Fathers' CDAS scores were not associated with child CFSS-DS, but showed a moderate correlation with child CDAS $(r=0.19, P<0.05)$. There were no significant differences in children's fear and anxiety based on age, sex, or socioeconomic variables. Children used internal coping strategies most frequently and external coping strategies were rated by the children as the most effective. We did not find differences in number and type of effective coping strategies in children with high DFA compared with children with low DFA. In conclusion, there is evidence of the coexistence of dental fear in parents and older children. These findings may help to devise interventions that will prevent or alleviate children's DFA.

Keywords: fear of dental pain, pain behavior, coping skills, adaptive behavior, school children, parents

\section{Introduction}

Dental anxiety is a fear of going to the dentist that may be a slight or very excessive dread of anything being done to the teeth. ${ }^{1}$ A review of studies in children and adolescents published in 2007 revealed that prevalence of dental fear and anxiety (DFA) varies from $6 \%$ to $20 \%$ in 12 different populations, with a mean of $11 \%$. $^{2}$ DFA is significantly associated with irregular use of dental services, avoiding and delaying dental treatment, and may also be a risk factor for higher caries incidence. ${ }^{3}$ Therefore, research aimed towards discovering and alleviating DFA may enhance oral health and quality of life. Understanding mechanisms responsible for development of a child's DFA would help to create appropriate interventions.

A number of factors have been associated with DFA - psychosocial, behavioral, sociodemographic, and genetic. It has been shown that adults have often already acquired dental anxiety from childhood. ${ }^{4}$ Painful and unpleasant stimuli associated with dental treatment may lead to the development of DFA. ${ }^{5}$ However, among children with comparable dental history, some have DFA, while others do not. ${ }^{5}$ Thus, it has 
been suggested that discrepancy between previous dental experiences and onset of anxiety and fears may be explained by differences in child rearing and personality traits. ${ }^{5}$ Selfperceived oral health has been significantly associated with parental support. ${ }^{6}$ Family environment and culture have been associated with dental phobias, and it has been hypothesized that family environment is a model for learning that influences development of dental anxiety. ${ }^{7}$

Existing evidence about parental effect on a child's DFA are conflicting. A structured review on the relationship between parental and child dental fear found that the dental fear in children under the age of 8 years is significantly related to dental fear in parents, but the relationship between parental and child DFA in older children and adolescents remains less clear. ${ }^{8}$

If parents serve as a model for development of DFA, interventions aimed towards parents may help to minimize development of DFA in children. Dental health professionals are other important figures, because they can control events in the dental setting and encourage helpful behavior. When a child has DFA, a dentist's treatment may consist of training the child's coping abilities. ${ }^{9}$ Since dental treatment is associated with stressful conditions, ${ }^{10}$ children may use a variety of coping strategies to deal with pain in dentistry. ${ }^{11}$ Stress has been defined as an orchestrated set of bodily defenses against any form of noxious stimulus, including psychological threats. ${ }^{12}$ While stress is an inevitable aspect of the human condition, it is coping that makes the big difference in adaptation to stress. ${ }^{13}$ Coping may be seen as a defense mechanism, which deals with threats to an individual's psychological integrity. ${ }^{14}$

There is some degree of differentiation in coping behavior of children that is specific to the dental visit. ${ }^{9,15}$ Knowing the level of a child's DFA may help dental staff to adjust treatment and their behavior to a child's specific needs, and to teach children how to use effective coping strategies.

The aim of this study was to test the hypothesis that there is a significant positive correlation between parental and child DFA, and that fearful children use more coping strategies.

\section{Methods}

\section{Ethics}

The study was approved by the Ethical Committee of the School of Medicine, University of Mostar and conducted in accordance with the Declaration of Helsinki. The surveys were undertaken with the understanding and written consent of the participants. Parents provided written informed consent for themselves. Additionally, written informed consent was obtained from the parents on the behalf of child participants involved in the study. The Ethics Committee approved the consent procedure.

\section{Participants}

This was an open descriptive study conducted in Krusevo primary school in Mostar, Bosnia and Herzegovina. All children attending this school (aged 7-15 years) and their biological parents were invited to participate in the study. All the children in the school had had previous experiences with a dentist due to the health service programs of the Community Health Center. Of 136 children in the school, parents of 114 children consented to participate $(84 \%)$. A group of 7-year-olds consisted of seven children, while in all other age groups there were 10-19 children. All children included in the study were healthy, without disorders that could influence anxiety and coping results. A sample size calculation indicated that with an estimated mediumeffect size of $r=0.43$ for the relationship between parental and children's dental fear scores, a two-sided significance level of $5 \%$ and a desired power of $80 \%$, a minimum of 32 patients is required.

\section{Study protocol and measures}

The participants received information about the study in the school. Inclusion criteria for children were as follows: minimum age of 7 years, to have at least one available parent for inclusion in the study, and consent for participation in the study. After consent, families were invited to the Community Health Center Krusevo, where questionnaires in the Croatian language were filled out.

Children and parents were separated to fill out the questionnaires on their own. Parents were not allowed to assist children in filling out the questionnaires.

Children filled out Dental Subscale of the Children's Fear Survey Schedule (CFSS-DS), which is the most widely used measure of dental fear for children. ${ }^{16}$ The development of the CFSS-DS is credited to Cuthbert and Melamed, who made modifications to the Child Fear Survey Schedule, which was, in turn, based on a general fear scale for adults. ${ }^{17}$ The CFSS-DS consists of 15 items, covering various aspects of dental and medical situations, and scored from 1 (not afraid) to 5 (very afraid) on a 5-point Likert scale, with total scores ranging from 15 to $75 .{ }^{17}$ The cutoff points for the CFSS-DS were as follows: children who scored above 32 on CFSS-DS were defined as borderline anxious children, while those who scored above 39 were defined as dentally anxious children. The CFSS-DS was translated into the Croatian language and validated. ${ }^{18}$ 
For assessment of coping strategies that a child would use when thinking of a painful situation at the dentist, the Dental Cope Questionnaire (DCQ) was used. The DCQ was developed as a specific pain-coping questionnaire by Versloot et $\mathrm{al}^{9}$ as a revised version of the Kidcope. The DCQ contains 15 coping strategies related to the dental setting, and the child is asked to rate use of each strategy in Part A by indicating "yes" or "no" and then to score perceived effectiveness of each strategy that is used by indicating "not at all," "a little," or "a lot" in the part B of the DCQ. ${ }^{9}$ Translation and validation of the DCQ was reported previously. ${ }^{19}$ The DCQ was translated in Croatian language according to the guidelines for the process of cross-cultural adaptation of self-report measures, using a series of translations and back-translations. ${ }^{20}$ The results indicated that the DCQ has good internal consistency. Test-retest reliability of DCQ was evaluated using Pearson correlations, with $r=0.68 .{ }^{19}$

Both children and parents filled out the Corah Dental Anxiety Questionnaire (CDAS). The CDAS was developed in $1969,{ }^{21}$ and it is the most widely used measure of dental anxiety. ${ }^{16}$ The CDAS has four items, about four dentally related situations, where respondents are asked to indicate which option is closest to their likely response to that situation. Items are scored on a scale of 1 (no anxiety) to 5 (extreme anxiety) and summed to give an overall anxiety score ranging from 4 to $20 .{ }^{21}$ The cutoff points for the CDAS were as follows: dental anxiety of the study participants was classified as moderate (CDAS score of 9-12), high (CDAS score of 13-14), or severe (CDAS score 15 or more) anxiety. ${ }^{22}$ Measures that were filled out by parents were examining their own anxiety. The CDAS was translated into the Croatian language and validated. ${ }^{18}$

Both children and parents completed a sociodemographic questionnaire, consisting of questions about age, sex, education, employment, marital status, and monthly income.

Data collected were entered into a spreadsheet. A code was assigned to each participant; only one author (AC) was familiar with the participants' identities, while patient data were anonymized for the other coauthors.

\section{Statistics}

Data were analyzed using SPSS (SPSS Inc., Chicago, IL, USA) 15.0 software. Total and subscale scores were calculated for questionnaires. Descriptive statistics were used for sociodemographic data. Where appropriate, data were expressed as mean and standard deviation. Internal consistency of the scales was assessed with Cronbach's alpha test. Differences between groups were assessed using Student's $t$-test when appropriate. For differences in coping strategies, we used chi-square test. Regression analysis was used to assess the contribution of fathers' and mothers' dental anxiety to their children's dental anxiety. Correlations were calculated with Pearson's test. Cronbach's alpha was used for calculating internal consistency of the questionnaire items. Statistical significance was set at $P<0.05$.

\section{Results \\ Sociodemographic data}

Of 136 children in the analyzed school, 114 participated in the study ( $84 \%), 58$ boys and 56 girls. Children were aged $7-15$ years ( $11.0 \pm 2.2$ years); both mean and median age of the children was 12 years. Mothers of all children participated in the study, while five fathers were either absent or deceased (Table 1). The majority of parents, both mothers and fathers, had secondary education, were employed, and had a monthly household income below US\$1,000 (Table 1). According to the Bosnia and Herzegovina's Federal Office of Statistics, average net salary in this country for June 2011 was US\$550. There were a few missing responses on some items of the sociodemographic questionnaire.

\section{Dental anxiety and fear}

CFSS-DS revealed that $11 \%$ of children had clinical dental fear (CFSS-DS score $\geq 39, \mathrm{~N}=12$ ), 14\% of children exhibited borderline fear (CFSS score $32-38, \mathrm{~N}=16$ ), and $75 \%$ of the children had no dental fear (CFSS score $<32, \mathrm{~N}=86$ ). No significant differences in CFSS-DS scores were found between boys and girls $(P=0.35)$.

Table I Parents' sociodemographic data

\begin{tabular}{|c|c|c|}
\hline Variable & Mothers $(\mathrm{N}=|| 4)$ & Fathers $(\mathrm{N}=109)$ \\
\hline Age, years $(M \pm S D)$ & $40.4 \pm 5.4$ & $45.1 \pm 5.6$ \\
\hline \multicolumn{3}{|l|}{ Education, N (\%) } \\
\hline Primary & $4(4)$ & $4(4)$ \\
\hline Secondary & $96(84)$ & $92(84)$ \\
\hline Higher education & $5(4)$ & $7(6)$ \\
\hline University & $8(7)$ & $4(4)$ \\
\hline \multicolumn{3}{|l|}{ Employed, N (\%) } \\
\hline Yes & $64(56)$ & $82(75)$ \\
\hline No & $50(44)$ & $22(20)$ \\
\hline \multicolumn{3}{|l|}{ Monthly income, N (\%) } \\
\hline Below I,000 USD & $61(54)$ & $56(5 \mathrm{I})$ \\
\hline I,000-2,000 USD & $46(40)$ & $47(43)$ \\
\hline Above 2,000 USD & $7(6)$ & $5(5)$ \\
\hline \multicolumn{3}{|l|}{ Marital status } \\
\hline Married & 112 & 109 \\
\hline Not married & I & 0 \\
\hline Widowed & 1 & 0 \\
\hline
\end{tabular}

Abbreviations: M, mean; SD, standard deviation. 
CDAS revealed that $11 \%$ of the children had high anxiety, while $7 \%$ exhibited severe anxiety. The majority of participants had low dental anxiety. High and severe anxiety scores were more common in children and fathers, compared with mothers (Table 2). The mean score of dental anxiety on CDAS in children was $8.7 \pm 3.7$; in mothers, 7.8 \pm 3.4 ; and in fathers, 7.9 \pm 3.7 . No significant differences in CDAS scores were found between boys and girls $(P=0.62)$. Comparison between prepubescent and pubescent children (cutoff: 11 years) revealed no significant difference in their dental anxiety $(P=0.68)$. The internal consistency of the CFSS-DS and CDAS was high: for the CFSS-DS, Cronbach's $\alpha=0.93$; and for CDAS, $\alpha=0.89$.

Socioeconomic variables, such as education, employment, profession, income, marital status, or number of children in a family, did not show significant correlation with DFA of children or parents.

Levels of children's DFA measured with CDAS and CFSS-DS were highly correlated $(r=0.87, P<0.001)$.

\section{A correlation between parental dental anxiety and children's fear of dental pain}

A significant correlation was found between children's CFSS-DS score and CDAS score of mothers $(r=0.35$, $P<0.001)$, but not with CDAS score of fathers $(r=0.17$, $P>0.08)$. A significant correlation was found between CDAS scores of children and both CDAS score of mothers ( $r=0.32$, $P<0.001)$ and fathers $(r=0.19, P<0.05)$. Multiple regression analysis was performed to assess the relationship between parental and children's CDAS scores. Regression analysis showed that only mother's results were predictive $(\beta=0.34$, $P<0.001)$ of children's CDAS score $\left(F_{(2,106)}=8.08, P<0.01\right.$, $\left.R^{2}=0.13\right)$. Regression model was also used to determine whether the same predictive pattern could be replicated for children's CFSS-DS and paternal CDAS. This model showed that only mothers' CDAS scores are a significant predictor

Table 2 Participants' levels of dental anxiety, as measured with the CDAS

\begin{tabular}{|c|c|c|c|}
\hline Anxiety score & $\begin{array}{l}\text { Children, } \\
\mathbf{N}(\%)\end{array}$ & $\begin{array}{l}\text { Mothers, } \\
\text { N (\%) }\end{array}$ & $\begin{array}{l}\text { Fathers, } \\
\text { N (\%) }\end{array}$ \\
\hline Low anxiety $($ CDAS $<9)$ & $64(56)$ & $76(56)$ & $71(65)$ \\
\hline $\begin{array}{l}\text { Moderate anxiety } \\
\text { (CDAS 9-12) }\end{array}$ & $29(26)$ & $28(25)$ & $22(20)$ \\
\hline $\begin{array}{l}\text { High anxiety } \\
\text { (CDAS I3-14) }\end{array}$ & $13(11)$ & $6(5)$ & $7(7)$ \\
\hline $\begin{array}{l}\text { Severe anxiety } \\
\text { (CDAS I5-20) }\end{array}$ & $8(7)$ & $4(4)$ & $9(8)$ \\
\hline
\end{tabular}

Abbreviation: CDAS, Corah Dental Anxiety Scale. for children's CFSS-DS scores $\left(R_{1}{ }_{1}=0.13, F_{1}=16.16, P=0.000\right.$, $\left.\mathrm{B}_{\mathrm{m}}=0.362, P<0.001\right)$.

\section{Dental coping strategies}

The DCQ revealed that on average, children used 8.8 \pm 2.2 strategies in response to dental pain. The three most frequent coping strategies were as follows: "I do what the dentist tells me to" (97\%), "I think it is good for my teeth" (93\%), and "I tell myself it will be over soon" (91\%) (Table 3). The three most effective strategies, when looking at the sum of response categories "a bit" and "very much" were as follows: "I think of other things" (92\%), "I tell myself it will be over soon" $(89 \%)$, and "I like it when the nurse holds my hand" (89\%) (Table 3).

Correlation between the percentage of children that use a strategy and the rated efficacy of that strategy was positive $(r=0.53)$. The internal consistency of the DCQ was moderate: Cronbach's alpha was 0.67 for the total questionnaire, 0.54 for Part A, and 0.77 for Part B.

For each group of questions in the DCQ, there is an underlying component that can be identified. The first group, with questions one to four, consists of destructive strategies that are unhelpful for the treatment such as getting angry or closing one's mouth. The efficacy rate of destructive strategies

Table 3 Percentage of children with different coping strategies and subjective reports of their efficacy, based on the DCQ

\begin{tabular}{|c|c|c|c|}
\hline \multirow[t]{2}{*}{$\begin{array}{l}\text { When I am in pain at the } \\
\text { dentist }\end{array}$} & \multirow[t]{2}{*}{ Yes (\%) } & \multicolumn{2}{|c|}{$\begin{array}{l}\text { When yes, does it } \\
\text { help? (\%) }\end{array}$} \\
\hline & & $\begin{array}{l}\text { Not at } \\
\text { all }\end{array}$ & $\begin{array}{l}\text { A bit or } \\
\text { very much }\end{array}$ \\
\hline \multicolumn{4}{|l|}{ Destructive } \\
\hline I get angry at mom and dad & 11.4 & 30.8 & 69.2 \\
\hline I think of a reason to sneak out & 16.7 & 26.3 & 73.7 \\
\hline I close my mouth & 21.9 & 20.0 & 80.0 \\
\hline I get angry at the dentist & $2 \mathrm{I} . \mathrm{I}$ & 29.2 & 70.8 \\
\hline \multicolumn{4}{|l|}{ External } \\
\hline I look at the mirror & 76.3 & 13.8 & 86.2 \\
\hline $\begin{array}{l}\text { I like it when the nurse holds } \\
\text { my hand }\end{array}$ & 49.1 & 10.7 & 89.3 \\
\hline I like it to have friends with me & 50.0 & 19.3 & 80.7 \\
\hline I tell the dentist & 83.3 & 11.6 & 88.4 \\
\hline $\begin{array}{l}\text { I ask the dentist what he is } \\
\text { doing }\end{array}$ & 43.9 & 26.0 & 74.0 \\
\hline \multicolumn{4}{|l|}{ Internal } \\
\hline I think it is part of dentistry & 89.5 & 36.3 & 63.7 \\
\hline I tell myself it will be over soon & 91.2 & 10.6 & 89.4 \\
\hline I think of other things & 71.9 & 8.5 & 91.5 \\
\hline $\begin{array}{l}\text { I think it is my own fault I have } \\
\text { cavities }\end{array}$ & 66.7 & 22.4 & 77.6 \\
\hline I think it is good for my teeth & 93.0 & 18.9 & $8 I .1$ \\
\hline I do what the dentist tells me to & 97.4 & 20.7 & 79.3 \\
\hline
\end{tabular}

Abbreviation: DCQ, Dental Cope Questionnaire. 
was $73.4 \%$, measured as the percentage of children that indicated that the strategies helped a bit or very much. Questions five to nine represent strategies where the person uses external help to cope, such as persons present in the room, and the efficacy of these strategies was $83.7 \%$. Questions nine to 15 indicate internal coping strategies that are more cognitive oriented, which help to counteract the negative feelings, and their efficacy rate was $80.4 \%$. The internal consistency of the DCQ was good, with $\alpha=0.70$.

\section{Dental coping strategies and children's DFA}

The number of coping strategies between children with clinical fear and low dental fear, as measured with CFSSDS did not differ. Also, no differences were found between the types of coping strategies used by children with clinical and low dental fear. When we compared coping strategies of children with different levels of anxiety measured with CDAS, the only difference was found for the strategy "I think of a reason to sneak out", this strategy was significantly more commonly used among children with low dental anxiety.

\section{Discussion}

The main finding of this study is that parental DFA is associated and predictive of children's DFA among children aged $7-15$ years. We did not find a difference in number of coping strategies used by children depending on their level of dental anxiety. According to our results, there were no significant differences in children's fear and anxiety based on age, sex, or socioeconomic variables.

A correlation found between children's and parental DFA indicates a fair relationship for maternal dental anxiety on both CFSS-DS and CDAS. Significant correlation between fathers' CDAS scores and children's CDAS scores was found, but the effect was small. Regression analyses showed that only maternal DFA was predictive of DFA in children. Our results could indicate that mother's behavior is more important than father's for development of DFA in a child. Mothers are usually more involved in childcare, which could explain this association.

Understanding how DFA is developed or learned by a child is important for reducing these fears in children. The majority of the psychological field believes fears are learned. If fear can be learned, it can also be unlearned. Vicarious learning, presumes that people can learn by observing the behavior of other individuals and the outcomes of those behaviors. ${ }^{23,24}$ We hypothesized that parents serve as a model for development of DFA. Parental behavior towards oral health may be considered a modeling process in which children imitate adult models. ${ }^{25}$ We have already shown in a previous study that parents may have a specific cognitive style for coping with pain, which influences children's responses to pain experiences. ${ }^{26}$ De Jongh et al ${ }^{27}$ confirmed that avoidance of dental care is linked to a deteriorated oral health and likelihood of experiencing fear of negative evaluation. Furthermore, it was suggested that patients with high dental anxiety would particularly benefit from interventions designed to break their avoidance pattern. ${ }^{27}$ Considering our results, it is possible that interventions aimed towards dentally anxious/fearful parents could help in reducing children's dental anxiety and oral health.

In a study examining how childhood dental treatment experiences of a group of parents influences dental treatment they accessed for their children who had dental decay and toothache, parents described their uneasiness about dental treatment for their children, indicating that parents remember their unpleasant childhood experiences in the dental setting and that they are repeating it with their own children. $^{28}$

A mother's positive attitude towards dental treatments in children aged 5-6 years is associated with lower caries incidence in children, better oral hygiene, and more frequent children's visits to a dentist. In a sample of 2 to 5 year old children and their mothers, it has been shown that maternal dental anxiety is associated with a higher prevalence of untreated dental caries. ${ }^{29}$ The same research group studied whether maternal dental anxiety has an influence on oral health-related quality of life of preschool children and they found that the parent distress domain is influenced by maternal anxiety, showing that anxious mothers have a tendency to report on feeling guilty or upset because of children's dental problems or treatment experience. ${ }^{30}$ In a sample of children whose mean age was 6 years, it has been shown that children with dental anxiety behave better when the parent is not present during the treatment. ${ }^{31}$

However, less is known about the association between parental and children's anxiety in school-aged children. A recent review of 43 studies published between 1968 and 2007 indicated that the majority of studies indicate a significant correlation between parental and child dental fear, but the relationship varies according to the choice of measures and age of children. ${ }^{8}$ The review authors indicated that further research is needed, and their specific recommendations were to narrow the age of studied children and to use valid and reliable measures. ${ }^{8}$ 
Subsequently, the relationship between dental fear in parents and children was studied in 7-12 year olds, and it was found that there was a significant association between maternal and children's dental fear, but not between fathers' and children's fear, but that fathers have a mediating role in the transmission of dental fear from the mother to the child. ${ }^{32}$ These findings are supported with our results.

In this study, we used two measures for assessing DFA that are validated for this construct. The CDAS is a measure originally developed for adults and older adolescents. It has been used for children before in a number of studies. However, it has been reported that CFSS-DS is preferred, as it has better psychometric properties. ${ }^{2}$ We used both CDAS and CFSS-DS among children in this study to see whether different instruments would yield the same results. The correlation coefficient can be used to compare measurements of different quantities, such as different scales for measuring anxiety. ${ }^{33}$ We found that children's results on CDAS and CFSS-DS were highly correlated $(r=0.87, P<0.001)$, and correlations above 0.75 indicate a very good or excellent relationship. Analyses of correlations with parental DFA scores measured with CDAS were similar with both measures, showing greater importance of mothers' dental anxiety.

Considering that dental care involves potentially painful and unpleasant stimuli that act as stressors and may lead to DFA, it is useful to examine coping strategies that may be used to deal with these stressors more efficiently. Analysis of dental coping strategies of children in our sample revealed that $7-15$ year olds use a variety of coping strategies. Internal strategies were used most frequently, and external coping strategies were rated by the children as the most effective. Our findings confirmed the results of Versloot et al, ${ }^{9}$ who found that external coping strategies were the most effective, followed by internal and destructive strategies. In our study, destructive strategies were much more effective than reported by Versloot et al, ${ }^{9}$ while the results for external and internal coping strategies were almost the same.

In a study on children's coping with pain during dental care, it was found that fearful children have a specific coping style compared with other children, they used more coping strategies and used internal coping strategies more frequently. In our study, we did not find differences in coping strategies used by anxious children, compared with children with low DFA.

Our study had several limitations. First, study design does not permit conclusions about causality. Second, we had a relatively homogenous group of school-aged children. Homogeneity of the group was also present in terms of lower sociodemographics of the whole studied population.

In conclusion, there is evidence of the coexistence of dental fear in parents and children. These findings may help to devise interventions that will prevent or alleviate children's DFA. Children's DFA might be reduced or prevented by influencing parental dental anxiety.

\section{Acknowledgments}

We are grateful to the study participants. We would also like to thank all the teachers from the Krusevo school for helping us to inform children and their parents about the study.

\section{Disclosure}

The authors report no conflicts of interest in this work.

\section{References}

1. Coriat IH. Dental anxiety; fear of going to the dentist. Psychoanal Rev. 1946;33:365-367.

2. Klingberg G, Broberg AG. Dental fear/anxiety and dental behaviour management problems in children and adolescents: a review of prevalence and concomitant psychological factors. Int J Paediatr Dent. 2007;17(6):391-406.

3. Vassend O. Anxiety, pain and discomfort associated with dental treatment. Behav Res Ther. 1993;31(7):659-666.

4. Holmes RD, Girdler NM. A study to assess the validity of clinical judgement in determining paediatric dental anxiety and related outcomes of management. Int J Paediatr Dent. 2005;15(3):169-176.

5. Krikken JB, Ten Cate JM, Veerkamp JS. Child dental fear and general emotional problems: a pilot study. Eur Arch Paediatr Dent. 2010;11(6):283-286.

6. Ostberg AL. On self-perceived oral health in Swedish adolescents. Swed Dent J Suppl. 2002;(155):1-87.

7. Kleinknecht RA, Klepac RK, Alexander LD. Origins and characteristics of fear of dentistry. J Am Dent Assoc. 1973;86(4):842-848.

8. Themessl-Huber M, Freeman R, Humphris G, MacGillivray S, Terzi N. Empirical evidence of the relationship between parental and child dental fear: a structured review and meta-analysis. Int J Paediatr Dent. 2010;20(2):83-101.

9. Versloot J, Veerkamp JS, Hoogstraten J, Martens LC. Children's coping with pain during dental care. Community Dent Oral Epidemiol. 2004;32(6):456-461

10. Akyuz S, Pince S, Hekin N. Children's stress during a restorative dental treatment: assessment using salivary cortisol measurements. J Clin Pediatr Dent. 1996;20(3):219-223.

11. Van Meurs P, Howard KE, Versloot J, Veerkamp JS, Freeman R. Child coping strategies, dental anxiety and dental treatment: the influence of age, gender and childhood caries prevalence. Eur J Paediatr Dent. 2005;6(4):173-178.

12. Selye H. A syndrome produced by diverse nocuous agents. 1936. J Neuropsychiatry Clin Neurosci. 1998;10(2):230-231.

13. Lazarus RS. Psychological Stress and the Coping Process. New York, NY: McGraw-Hill; 1966.

14. Lazarus RS. Coping theory and research - past, present, and future. Psychosom Med. 1993;55(3):234-247.

15. Curry SL, Russ SW. Identifying coping strategies in children. J Clin Child Psychol. 1985;14(1):61-69.

16. Armfield JM. How do we measure dental fear and what are we measuring anyway? Oral Health Prev Dent. 2010;8(2):107-115.

17. Cuthbert MJ, Melamed BG. A screening device: children at risk for dental fears and management problems. J Dent Child. 1982;49:432-436. 
18. Majstorovic M, Veerkamp JS, Skrinjaric I. Reliability and validity of measures used in assessing dental anxiety in 5- to 15-year-old Croatian children. Eur J Paediatr Dent. 2003;4(4):197-202.

19. Coric A. Association between Dental Anxiety and Oral Health [master's thesis]. Mostar, Bosnia and Herzegovina; 2011.

20. Beaton DE, Bombardier C, Guillemin F, Ferraz MB. Guidelines for the process of cross-cultural adaptation of self-report measures. Spine. 2000;25(24):3186-3191.

21. Corah NL. Development of a dental anxiety scale. J Dent Res. 1969;48(4):596.

22. Corah NL, Gale EN, Illig SJ. Assessment of a dental anxiety scale. J Am Dent Assoc. 1978;97(5):816-819.

23. Rachman $\mathrm{S}$. The conditioning theory of fear-acquisition: a critical examination. Behav Res Ther. 1977;15(5):375-387.

24. Do C. Applying social learning theory to children with dental anxiety. J Contemp Dent Pract. 2004;5(1):126-135.

25. Okada M, Kawamura M, Kaihara Y, et al. Influence of parents' oral health behaviour on oral health status of their school children: an exploratory study employing a causal modelling technique. Int J Paediatr Dent. 2002;12(2):101-108.

26. Kraljevic S, Banozic A, Maric A, Cosic A, Sapunar D, Puljak L. Parents' pain catastrophizing is related to pain catastrophizing of their adult children. Int J Behav Med. 2012;19(1):115-119.
27. De Jongh A, Schutjes M, Aartman IH. A test of Berggren's model of dental fear and anxiety. Eur J Oral Sci. 2011;119(5):361-365.

28. Smith PA, Freeman R. Remembering and repeating childhood dental treatment experiences: parents, their children, and barriers to dental care. Int J Paediatr Dent. 2010;20(1):50-58.

29. Goettems ML, Ardenghi TM, Romano AR, Demarco FF, Torriani DD. Influence of maternal dental anxiety on the child's dental caries experience. Caries Res. 2012;46(1):3-8.

30. Goettems ML, Ardenghi TM, Romano AR, Demarco FF, Torriani DD. Influence of maternal dental anxiety on oral health-related quality of life of preschool children. Qual Life Res. 2011;20(6):951-959.

31. Cox IC, Krikken JB, Veerkamp JS. Influence of parental presence on the child's perception of, and behaviour, during dental treatment. Eur Arch Paediatr Dent. 2011;12(4):200-204.

32. Lara A, Crego A, Romero-Maroto M. Emotional contagion of dental fear to children: the fathers' mediating role in parental transfer of fear. Int J Paediatr Dent. 2012;22(5):324-330.

33. Bland JM, Altman DG. Measurement error and correlation coefficients. BMJ. 1996;313(7048):41-42.
Journal of Pain Research

\section{Publish your work in this journal}

The Journal of Pain Research is an international, peer-reviewed, open access, online journal that welcomes laboratory and clinical findings in the fields of pain research and the prevention and management of pain. Original research, reviews, symposium reports, hypothesis formation and commentaries are all considered for publication.

\section{Dovepress}

The manuscript management system is completely online and includes a very quick and fair peer-review system, which is all easy to use. Visit http://www.dovepress.com/testimonials.php to read real quotes from published authors. 